\title{
Impact of Sustained Transforming Growth Factor- $\beta$ Receptor Inhibition on Chromatin Accessibility and Gene Expression in Cultured Human Endometrial MSC
}

\begin{abstract}
Raffaella Lucciola, $1,2,3$, Pavle Vrljicak ${ }^{3,4}$, Shanti Gurung ${ }^{1}$, Caitlin Filby',2, Saeedeh Darzi ${ }^{1,2}$, Joanne Muter ${ }^{3,4}$, Sascha Ott ${ }^{3,4}$, Jan J. Brosens ${ }^{3,4}$ and Caroline E. Gargett ${ }^{1,2 \star}$

${ }^{1}$ The Ritchie Centre, Hudson Institute of Medical Research, Melbourne, VIC, Australia, ${ }^{2}$ Department of Obstetrics and Gynaecology, Monash University, Melbourne, VIC, Australia, ${ }^{3}$ Division of Biomedical Sciences, Warwick Medical School, University of Warwick, Coventry, United Kingdom, ${ }^{4}$ Tommy's National Centre for Miscarriage Research, Warwick Medical School, University Hospitals Coventry and Warwickshire National Health Service Trust, Coventry, United Kingdom
\end{abstract}

OPEN ACCESS

Edited by:

Guido Moll,

Charité - Universitätsmedizin Berlin

Germany

Reviewed by:

Lorena Braid,

Aurora BioSolutions Inc., Canada

Martin Johannes Hoogduijn,

Erasmus University Rotterdam,

Netherlands

*Correspondence:

Caroline E. Gargett

caroline.gargett@hudson.org.au

Specialty section:

This article was submitted to

Stem Cell Research,

a section of the journal

Frontiers in Cell and Developmental

Biology

Received: 30 May 2020

Accepted: 13 August 2020

Published: 01 September 2020

Citation:

Lucciola R, Vrljicak P, Gurung $S$

Filby C, Darzi S, Muter J, Ott S,

Brosens JJ and Gargett CE (2020) Impact of Sustained Transforming

Growth Factor- $\beta$ Receptor Inhibition on Chromatin Accessibility and Gene Expression in Cultured Human Endometrial MSC.

Front. Cell Dev. Biol. 8:567610. doi: 10.3389/fcell.2020.567610
Endometrial mesenchymal stem cells (eMSC) drive the extraordinary regenerative capacity of the human endometrium. Clinical application of eMSC for therapeutic purposes is hampered by spontaneous differentiation and cellular senescence upon large-scale expansion in vitro. A83-01, a selective transforming growth factor- $\beta$ receptor (TGF $\beta-R$ ) inhibitor, promotes expansion of eMSC in culture by blocking differentiation and senescence, but the underlying mechanisms are incompletely understood. In this study, we combined RNA-seq and ATAC-seq to study the impact of sustained TGF $\beta$ $\mathrm{R}$ inhibition on gene expression and chromatin architecture of eMSC. Treatment of primary eMSC with A83-01 for 5 weeks resulted in differential expression of 1,463 genes. Gene ontology analysis showed enrichment of genes implicated in cell growth whereas extracellular matrix genes and genes involved in cell fate commitment were downregulated. ATAC-seq analysis demonstrated that sustained TGF $\beta-R$ inhibition results in opening and closure of 3,555 and 2,412 chromatin loci, respectively. Motif analysis revealed marked enrichment of retinoic acid receptor (RAR) binding sites, which was paralleled by the induction of $R A R B$, encoding retinoic acid receptor beta (RAR $\beta$ ). Selective RAR $\beta$ inhibition attenuated proliferation and clonogenicity of A83-01 treated eMSC. Taken together, our study provides new insights into the gene networks and genome-wide chromatin changes that underpin maintenance of an undifferentiated phenotype of eMSC in prolonged culture.

Keywords: endometrium, mesenchymal stem cell, human, chromatin, gene regulatory networks, transforming growth factor receptor beta, retinoic acid receptor beta

\section{INTRODUCTION}

The human endometrium is a highly dynamic tissue that generates $4-10 \mathrm{~mm}$ of mucosa in each menstrual cycle (Jabbour et al., 2006). This extraordinary regenerative capacity is mediated by resident epithelial progenitors and mesenchymal stem/stromal cells (MSC) (Chan et al., 2004; Gargett et al., 2016). Cultured endometrial MSC (eMSC) are clonogenic, highly proliferative, 
multipotent, and express the International Society for Cellular Therapies (ISCT) surface markers (Gargett et al., 2009). Human eMSC can be purified as $\mathrm{CD} 140 \mathrm{~b}^{+} \mathrm{CD} 146^{+}$cells (Schwab and Gargett, 2007), or by means of the surface marker SUSD2 (Sushi Domain-containing 2, formerly W5C5) (Masuda et al., 2012). While eMSC also express Stro-1, this marker does not enrich for clonogenic cells (Schwab et al., 2008). eMSC further express MSCA-1 (Sobiesiak et al., 2010). These markers identify eMSC as pericytes and perivascular cells of endometrial spiral arterioles, arterioles and venules (Gargett and Masuda, 2010; Murakami et al., 2014; Lucas et al., 2016; Bozorgmehr et al., 2020). A major advantage of the endometrium over other sources of adult MSC, such as bone marrow or adipose tissue, is its accessibility. Endometrial sampling is a routine office-based procedure that does not require anesthesia (Gargett and Masuda, 2010).

Preclinical animal studies showed that eMSC are a promising cell source for treatment of gynecological disorders, including pelvic organ prolapse (Darzi et al., 2016; Gargett et al., 2019). For example, eMSC seeded or bio-printed onto meshes with biomechanical properties matching the human vagina (e.g., nondegradable polyamide/gelatin composite meshes) (Ulrich et al., 2014; Emmerson et al., 2019), or on degradable nanofibers (Mukherjee et al., 2019b; Paul et al., 2019), promote angiogenesis, collagen deposition, and cellular infiltration into biomaterials when transplanted into rodent or ovine models. They also elicit an early inflammatory response, characterized first by influx of M1 macrophages, which then switch to the M2 wound healing phenotype (Ulrich et al., 2014; Darzi et al., 2018). In vitro, eMSC seeded on polyamide/gelatin meshes differentiate into smooth muscle cells and fibroblasts; cell types that are important for restoring vaginal structure and function ( $\mathrm{Su}$ et al., 2014). Hence, the endometrium is a rich source of MSC for autologous and allogenic cell-based therapies, including pelvic organ prolapse, urinary incontinence, and regeneration of scarred endometrium in women with Asherman's syndrome (Ulrich et al., 2013; Gargett et al., 2016; Simoni and Taylor, 2018).

Clinical application of eMSC requires expansion of cells in culture (Gurung et al., 2015; Darzi et al., 2016). As is the case for MSC from other sources (Baxter et al., 2004), eMSC cultured over several passages differentiate spontaneously into endometrial stromal fibroblasts as shown by signature gene profiles and are subjected to replicative stress caused by telomere shortening (Gurung et al., 2015, 2018b; Barragan et al., 2016). Consequently, the cells lose their proliferative capacity as well as the ability to reconstitute tissue in vivo (Baxter et al., 2004). To overcome this impediment to the clinical translation, we and others have explored the use of small molecules to maintain the in vivo properties of eMSC and MSC in prolonged culture (Al-Habib et al., 2013; Gurung et al., 2015, 2018b). In particular, we focused on blocking the TGF $\beta$ receptor signaling pathway as it is one of the main pathways inducing MSC differentiation ( $\mathrm{Ng}$ et al., 2008). A83-01 is also used to prevent spontaneous differentiation of human pluripotent stem cells (Li and Ding, 2010) and organoid cultures for a range of epithelial cell types (Sato and Clevers, 2013). We recently reported that A83-01, a selective inhibitor of TGF- $\beta$ type I receptor (TGF $\beta$-R) ALK4, 5 and 7 kinase, increases proliferation and inhibits apoptosis and senescence of cultured eMSC, thereby safeguarding their functional properties in vitro (Gurung et al., 2015, 2018b) and prolonging their survival in vivo (Gurung et al., 2018a). Further, A83-01-treated eMSC maintain multipotency, exhibit increased angiogenic activity, express a proangiogenic, antifibrotic, and immunomodulatory gene profile and enhanced secretory profile of angiogenic and immunomodulatory factors (Gurung et al., 2015, 2018b).

The mechanisms underlying the expansion of cultured eMSC in response to sustained TGF $\beta$-R inhibition are incompletely understood. Adult stem/progenitor cells have more open chromatin than their differentiated progeny, but less than pluripotent stem cells. Further dynamic chromatin changes underpin subsequent differentiation into mesodermal lineages (Chen and Dent, 2014), including fibroblasts. Based on these observations, we hypothesized that sustained TGF $\beta$-R inhibition leads to divergence in the chromatin landscape of cultured eMSC and activation of transcriptional regulatory circuitries that maintain the cells in a more naïve or undifferentiated state. To test this hypothesis, eMSC cultured with or without A8301 were subjected to integrated RNA-sequencing (RNA-seq) and Assay for Transposase Accessible Chromatin through sequencing (ATAC-seq). Our findings provide new insights into the mechanisms of action of TGF $\beta$-R inhibition that may lead to the development of more targeted pharmacological approaches for eMSC expansion, thereby enhancing their functional properties for clinical translation.

\section{MATERIALS AND METHODS}

\section{Endometrial Biopsies}

The study was approved by the Monash Health and Monash University Human Research Ethics committees. Endometrial biopsies were obtained from seven pre-menopausal women, without endometrial pathologies, following written informed consent and according to The Declaration of Helsinki (2000) guidelines. Participant information is kept confidential and samples deidentified prior to use. None of the participants received hormonal treatment within 3 months prior to the biopsy.

\section{eMSC Isolation and Culture}

Endometrial biopsies were processed and single-cell suspensions of eMSC obtained as described previously (Masuda et al., 2012). Briefly, finely minced endometrial tissue was enzymatically and mechanically digested in Dulbecco's modified Eagle's medium (DMEM/F12) supplemented with collagenase type I and DNase I (Worthington Biochemical Corporation, United States) at $37^{\circ} \mathrm{C}$ on a rotating MACSmix (Miltenyi Biotec, United States) for $60 \mathrm{~min}$. The digested tissue was filtered through $40 \mu \mathrm{m}$ strainers (Becton Dickinson, BD, United States) to remove gland fragments, washed, red blood cells removed using Ficoll-Paque (GE healthcare Bio-science, United States) density gradient separation at $1500 \mathrm{rpm}$ for $15 \mathrm{~min}$, and the interface containing stromal cells was washed in DMEM/F12/10\% fetal calf serum (FCS, Invitrogen, United States) and 1\% primocin (Life 
Technologies, United States). Single-cell suspensions were resuspended in separation buffer (0.5\% FCS/PBS), and incubated with $10 \mu \mathrm{g} / \mathrm{ml}$ phycoerythrin (PE)-conjugated anti-human SUSD2 (BioLegend, United States) in the dark at $4^{\circ} \mathrm{C}$ for $30 \mathrm{~min}$. Cells were then washed, the cell pellet re-suspended in $20 \mu \mathrm{l}$ of anti-PE magnetic-activated cell sorting (MACS) microbeads (Miltenyi Biotec) with $80 \mu \mathrm{L}$ separation buffer and incubated in the dark at $4^{\circ} \mathrm{C}$ for $30 \mathrm{~min}$. The cells were washed, re-suspended in separation buffer $500 \mu \mathrm{L}$ and applied to a Miltenyi column (Miltenyi Biotech) in a magnetic field. Columns were washed three times with buffer. Magnetically labeled SUSD2 ${ }^{+}$eMSC were eluted with buffer and cell number was determined using Koya glasstic slides (KOVA International, United States).

eMSC were cultured in DMEM/F12 medium containing $10 \% \mathrm{FCS}, 1 \%$ primocin and $2 \mathrm{mM}$ glutamine (Invitrogen), supplemented with $10 \mathrm{ng} / \mathrm{ml}$ basic fibroblast growth factor (bFGF) (Peprotech, United States) and scaled-down to an in-house DMEM/F12 serum free medium (SFM) over $48 \mathrm{~h}$ within the first passage and incubated at $37^{\circ} \mathrm{C}$ in $5 \% \mathrm{CO}_{2} / 5 \%$ $\mathrm{O}_{2} / 90 \% \mathrm{~N}_{2}$, since this physiological $\mathrm{O}_{2}$ concentration favored eMSC expansion as described previously (Rajaraman et al., 2013), with $1 \mu \mathrm{M}$ TGF $\beta$-R inhibitor, A83-01 (Tocris Bioscience, United States) or vehicle control (0.01\% DMSO). Cells were seeded at 5,000 cells $/ \mathrm{cm}^{2}$ with medium changed every $48 \mathrm{~h}$ and passaged on days 15, 22, 29, and 36 into fibronectincoated (10 $\mu \mathrm{g} / \mathrm{ml}$; BD, United States) culture flasks as described previously (Gurung et al., 2015). At each passage, cells were counted using Kova glasstic slides and cumulative cell population (total cell number) calculated by multiplying total number of cells yielded at the current passage by total number of cells yielded at the previous passage and then dividing by the number of cells seeded at the current passage, as described previously (Gargett et al., 2009). At passage 4 (i.e., 36 days in culture), untreated and A83-01-treated eMSC cultures were subjected to functional assays, and RNA- and ATAC-seq.

\section{Flow Cytometry}

The surface phenotype of untreated and A83-01-treated eMSC was assessed by flow cytometry for three MSC markers [SUSD2, CD140b (Platelet-derived growth factor receptor $\beta$ ) and CD90 (Thy-1)] as described previously (Gurung et al., 2015). Cells were incubated for $1 \mathrm{~h}$ with 1:20 primary or matched isotype control antibodies in PBS containing 2\% FCS at $4^{\circ} \mathrm{C}$ in dark. The primary antibodies were APC-conjugated SUSD2 (Biolegend), PE-conjugated CD140b (R\&D Systems, United States) and APC-conjugated CD90 (BD Pharmingen, United States). Cells were washed with $2 \%$ FCS/PBS and fixed with 1:1 4\% paraformaldehyde in 2\% FCS/PBS. eMSC were analyzed using BD FACSCanto II (BD) (10,000 events/sample) and FlowJo v.10 software.

\section{Colony-Forming Unit-Fibroblast (CFU-F) Assay}

eMSC were cultured with or without A83-01 for 3 passages (36 days) and then seeded at 50 cells $/ \mathrm{cm}^{2}$ to assess cloning efficiency as described previously (Gurung et al., 2015), with minor modifications. Briefly, eMSC were seeded on fibronectincoated $10 \mathrm{~mm}$ culture dishes and cultured in SFM, supplemented with bFGF and EGF (both $10 \mathrm{ng} / \mathrm{mL}$; Invitrogen), in the presence or absence of A83-01 (1 $\mu \mathrm{M})$ in SFM at $37^{\circ} \mathrm{C}$ in $5 \% \mathrm{CO}_{2}, 5 \%$ $\mathrm{O}_{2}, 90 \% \mathrm{~N}_{2}$ for 2 weeks, with weekly medium changes. Cultures were then fixed in $10 \%$ formalin and stained with hematoxylin (Amber Scientific, United States), washed and blued in Scott's tap water. Colonies were counted and colony efficiency determined by dividing total number of colonies by number of cells seeded and multiplied by 100 .

\section{RNA Extraction, RNA Quality Control and RNA Libraries}

Total RNA was extracted from untreated and A83-01-treated eMSC using RNeasy Mini kit (Qiagen, Germany) according to the manufacturer's instructions, with some variations. Briefly, eMSC were trypsinised using TrypLE ${ }^{\mathrm{TM}}$ (Life Technologies), resuspended in DMEM/F12 containing 5\% Albumax II and then centrifuged at $300 \mathrm{~g}$ for $5 \mathrm{~min}$. Cell were lysed with RNeasy Lysis Buffer, genomic DNA contamination removed with RNasefree DNase (Qiagen) and RNA eluted with 30-50 $\mu$ l RNase-free water. RNA quality was assessed on an Agilent Technologies 2100 Bioanalyzer according to the manufacturer's instructions. Samples with RNA Integrity Number (RIN) $>8$ were subjected TruSeq Poly-A mRNA Library Pro Kit protocol 15031047 RevD (Illumina, United States) to generate indexed cDNA libraries. The library size was assessed on an Agilent Bioanalyzer and quantified by Qubit and qPCR.

\section{RNA-Seq}

RNA libraries were sequenced by Illumina HiSeq3000. Fifty million single-end reads were sequenced per sample with a read length of $50 \mathrm{bp}$. Transcriptomic maps were identified using Bowtie-2.2.3 (Langmead and Salzberg, 2012) and Samtools-1.2.0 (Li et al., 2009) against the UCSC hg19 transcriptome reference from the Illumina iGenomes resource. Counts were assessed using HTSeq -0.6.1 (Anders et al., 2015) and transcripts per million (TPM) were calculated. DESeq2 (Anders and Huber, 2010) was used for detection of differentially expressed genes in a pair-wise manner. Differentially expressed genes were subjected to Gene Ontology (GO) and KEGG Pathway enrichment analyses using the Database for Annotation, Visualization and Integrated Discovery (DAVID) version 6.8 (Huang da et al., 2009) and visualized using Reduce and Visualize Gene Ontology (REVIGO) online software (Supek et al., 2011). Fastq, metadata spreadsheet and table of counts have been deposited in the National Centre for Biotechnology Information Gene Expression Omnibus/sequence Read Archive with GEO (NCBI) accession number SuperSeries GSE146067/SubSeries GSE146066.

\section{ATAC-Seq}

ATAC-seq was performed as described (Buenrostro et al., 2013), although with some modifications (Vrljicak et al., 2018). Briefly, cells were washed with cold PBS, lysed using cold EZ lysis buffer (10 mM Tris-HCl, pH 7.4, 10 mM NaCl, 3 mM MgCl2 and $0.1 \%$ IGEPAL CA-630, Sigma-Aldrich, United Kingdom), 
transferred to chilled nuclease-free tubes, vortexed, left on ice for $5 \mathrm{~min}$, and then pelleted in a refrigerated centrifuge. The nuclear pellet was washed in EZ lysis buffer and re-suspended in the transposase reaction mix containing $25 \mu \mathrm{l}$ Tagment DNA (TD) Buffer, $5 \mu \mathrm{l}$ Tagment DNA Enzyme and $20 \mu$ l nuclease free water (Nextera DNA Sample Preparation Kit, Illumina, United Kingdom) for $45 \mathrm{~min}$ at $37^{\circ} \mathrm{C}$. Samples were purified using a Zymo DNA Clean and Concentrator-5 Purification kit (Zymo Research, United States). Briefly, DNA binding buffer was added to $50 \mu$ l samples, mixed and transferred to the column, centrifuged at $17,000 \mathrm{~g}$ for $30 \mathrm{~s}$ at RT, $200 \mu \mathrm{l}$ DNA wash buffer added, columns centrifuged and repeated twice. After removing the residual liquid, $23 \mu \mathrm{l}$ pre-warmed elution buffer was added and incubated for $2 \mathrm{~min}$ at RT, then centrifuged for $2 \mathrm{~min}$ to elute DNA. Twenty $\mu \mathrm{l}$ samples were added to PCR tubes containing $5 \mu \mathrm{l}$ index 1, $5 \mu \mathrm{l}$ index 2, $15 \mu \mathrm{l}$ Master mix (NPM), $5 \mu$ l Primer Cocktail (Nextera DNA Sample Preparation Kit and Nextera Index Kit, Illumina). Amplification was performed in a Veriti 96 Well Thermal Cycler (Applied Biosystems, United States) using the following PCR conditions: $72^{\circ} \mathrm{C}$ for $3 \mathrm{~min}, 98^{\circ} \mathrm{C}$ for $30 \mathrm{~s}$ then 15 cycles of $98^{\circ} \mathrm{C}$ for $10 \mathrm{~s}, 63^{\circ} \mathrm{C}$ for $30 \mathrm{~s}, 72^{\circ} \mathrm{C}$ for $1 \mathrm{~min}$. Libraries were purified using AMPure $\mathrm{XP}$ beads using the Illumina Nextera kit recommended protocol and quantified using Qubit HS DNA Assay on a Qubit 2.0 Fluorometer. Library sizes were assessed by Agilent Bioanalyzer using the High Sensitivity DNA chip. ATAC-seq library samples were sequenced on an Illumina HiSeq 1500 to a depth of thirty million paired-end reads/sample, with a read length of 100 bp. ATACseq data from this study have been deposited in the GEO (NCBI) under the accession number SuperSeries GSE146067/SubSeries146065.

\section{ATAC-Seq Data and Motif Analyses}

Sequenced paired-end reads were aligned to the University of California Santa Cruz (UCSC) human genome 19 (hg19) assembly using Bowtie2-2.2.6 (Langmead and Salzberg, 2012) and Samtools-1.2.0 (Li et al., 2009) and peak calling performed using MACS-2.1.0. HTSeq-0.6.1 (Anders et al., 2015) to count the reads overlapping the peaks and differential expression analysis of sequencing data 2 (DESeq2) was used to determine opening and closing regions of the chromatin (Anders and Huber, 2010). Fastq, metadata spreadsheet and table of counts have been deposited in the National Centre for Biotechnology Information Gene Expression Omnibus/sequence Read Archive with GEO accession number GSE146065. Differential open chromatin regions were mapped to cis-regulatory elements of their proximal genes using ENCODE DNaseI hypersensitivity data (Thurman et al., 2012). Physical interaction and distance no greater than $10 \mathrm{~kb}$ were used as criteria to assess association between ATAC-seq peak and proximal gene regulatory element. De novo short sequence motif analysis using Hypergeometric Optimization of Motif Enrichment (HOMER) v.4.8 was performed on 3,555 opening and 2,412 closing ATAC-seq peaks to determine enrichment and depletion of TF short sequence binding motifs in the differential ATAC-seq peaks (Heinz et al., 2010).

\section{RAR $\beta$ Inhibition Experiments}

Passage 3 cultured eMSC from 4 biological samples were treated with $1 \mu \mathrm{M}$ A83-01 or 0.01\% DMSO (vehicle control) for 7 days, then trypsinized and seeded in triplicate at 1000 cells/well $\left(3.125 \times 10^{3}\right.$ cells $\left./ \mathrm{cm}^{2}\right)$ into fibronectin-coated wells of two 96 well plates per biological replicate to assess proliferation on day 0 (D0) and day 3 (D3) in the presence or absence of $10 \mu \mathrm{M}$ RAR $\beta$ antagonist LE135 (Tocris Bioscience) using the cell viability MTS assay. After seeding, cells were allowed to adhere for $1 \mathrm{~h}$ before addition of $100 \mu \mathrm{l}$ medium containing A83-01 + LE135 or A83-01 + DMSO. After $2 \mathrm{~h}$, the MTS reagent $(20 \mu \mathrm{l}$, CellTiter 96 AQueous One Solution Cell Proliferation Assay, Promega, United States) was added to wells for the D0 timepoint and incubated for $2.25 \mathrm{~h}$ in the dark, then absorbance read at $490 \mathrm{~nm}$ on a spectrophotometer (Spectramax i3, Molecular Devices, United States). The medium was changed on the D3 plate at $24 \mathrm{~h}$ and the viability assay completed $72 \mathrm{~h}$ after seeding, as described above. Parallel cultures were subjected to CFU-F assays. Data were corrected for background readings (medium only) for each plate and normalized to D0 A83-01 for each sample and reported as fold-change.

\section{Statistical Analysis}

Statistical analyses were performed with GraphPad Prism 8. Technical replicates were inspected for outliers, which were removed from the analysis using Grubbs test. Normality of the data was determined with Shapiro-Wilk normality test. Individual data points and mean \pm standard error of the mean (SEM) are shown when appropriate. Statistical significance was determined using two-way analysis of variance (ANOVA) or ratio paired $t$-tests with $p<0.05$ considered statistically significant. For RNA-seq data analysis, statistical significance was assessed using the Benjamini-Hochberg procedure to control false discovery rate. Changes in gene expression were deemed statistically significant if the adjusted $p$-value ( $q$-value) was less than 0.05 .

\section{RESULTS}

\section{Phenotypic Characterization of Sustained A83-01-Treated eMSC}

We previously demonstrated that late passage eMSC cultured for just 7 days with the TGF $\beta-R$ signaling pathway inhibitor, A83-01, in SFM retain their SUSD2 ${ }^{+}$phenotype and function (Gurung et al., 2015). Apoptosis and senescence were prevented in these short term A83-01-cultured eMSC. To investigate if eMSC can be expanded more efficiently when maintained under sustained TGF $\beta$-R inhibition from culture initiation, cells isolated from 3 individual biopsies were seeded at 5000 cells $/ \mathrm{cm}^{2}$ in SFM supplemented with either A83-01 or vehicle (DMSO). The medium was refreshed every $48 \mathrm{~h}$ and cumulative cell population calculated at each passage (culture days 15, 22, 29, and 36). As shown in Figure 1A, treatment of eMSC with A83-01 from culture initiation progressively conferred a proliferative advantage. After 36 days in culture, at least one 
A

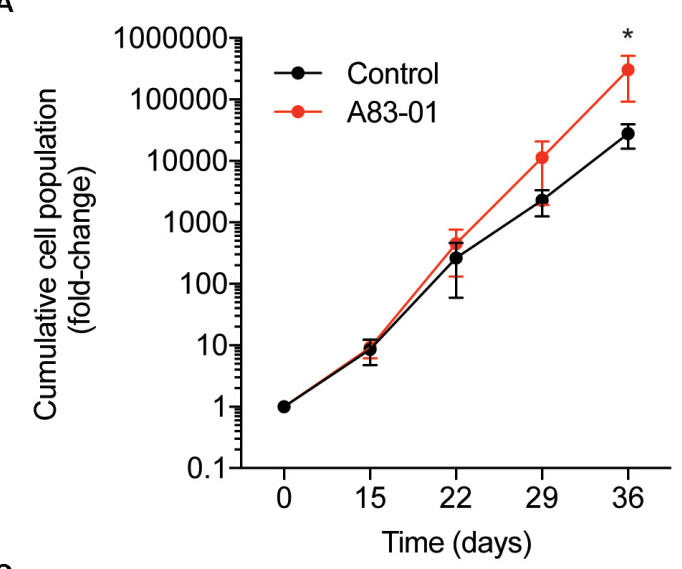

c

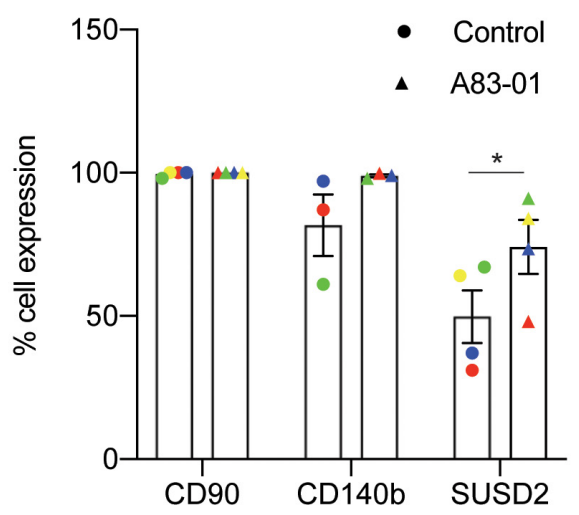

B

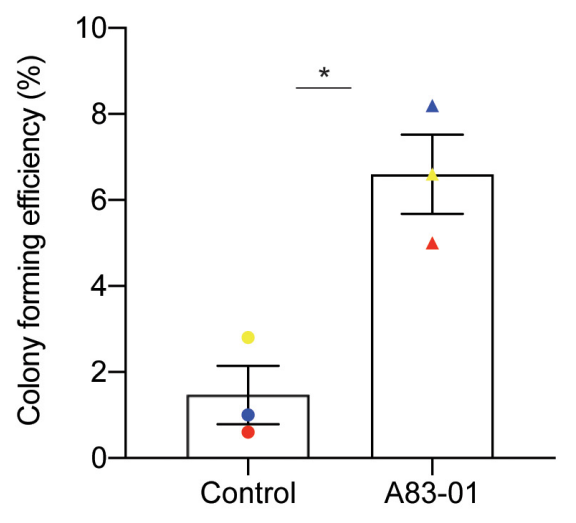

D

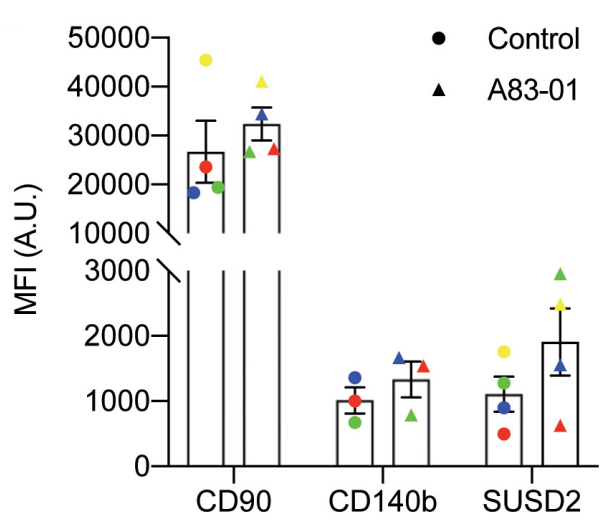

FIGURE 1 | Sustained TGF $\beta$-R inhibition modulates eMSC function and phenotype in culture. Primary human eMSC, isolated using SUSD2 magnetic bead sorting, were cultured with or without $1 \mu \mathrm{M}$ A83-01 in 5\% O2 for 36 days. (A) Cumulative cell population in eMSC cultures. Data are mean \pm SEM; ${ }^{*} p<0.05$. Note the logarithmic scale of the $Y$-axis. (B) Clonogenicity of 3 independent MSC cultures following 36 days culture in SFM with and without A83-01. Surface phenotype assessed by flow cytometry of eMSC cultures after 36 days with or without A83-01 shown as (C) \% positive cells and (D) MFI for CD90, CD140b and SUSD2. Data are mean \pm SEM of $n=4$ (except for CD140b where $n=3$ ) individual eMSC lines. Individual samples are shown in as different colored data points. ${ }^{*} p=0.039$ from control.

order of magnitude more cells were produced in the A8301 medium when compared to control medium (Figure 1A). Next, we performed colony-forming unit-fibroblast (CFU-F) assays on eMSC first cultured with or without A83-01 for 3 passages (36 days) and then seeded at a low density (50 cells $/ \mathrm{cm} 2$ ) to allow colony formation for a further 14 days. In keeping with our previous study (Gurung et al., 2015), exposure of cultured eMSC to A83-01 increased the CFU-F activity of primary cultures between $\sim 4$-10-fold ( $p=0.0146$; Figure 1B). We then chose the 36-day timepoint (Figure 1A) to analyze A83-01-treated cells for the expression of phenotypic eMSC markers CD140b, SUSD2, and CD90 as a representative ISCT marker, by flow cytometry. The abundance of $\mathrm{CD}^{+} 0^{+}$cells was $99.1 \pm 0.5 \%(n=4)$ for the control and did not change upon TGF $\beta$-R blockade (99.7 $\pm 0.2 \%, n=4$ ) (Figure 1C). Similarly, CD140b did not change following prolonged A8301 treatment $(81.7 \pm 10.7 \%$ vs. $98.9 \pm 0.5 \%(n=3)$. In contrast, A83-01 treatment increased the abundance of SUSD2 ${ }^{+}$ cells from $49.8 \pm 9.2 \%$ to $74.1 \pm 9.4 \%(n=4, p=0.011)$ (Figure 1C). Mean fluorescence intensity (MFI) was also calculated to evaluate the abundance of different cell surface molecules/cell. The MFI for CD90, CD140b and SUSD2 did not increase (Figure 1D) in response to prolonged A83-01 treatment, although there was a trend for SUSD2 (1108 \pm 269 vs. $1907 \pm 516$, $n=4, p=0.089$ ).

\section{Transcriptional Profiling of Sustained A83-01-Treated eMSC}

To explore how cultured eMSC are maintained in a more naïve state upon sustained TGF $\beta$-R inhibition, three independent cultures treated with or without A83-01 for 36 days were subjected to RNA-seq. Principal component analysis revealed that the greatest variation in gene expression is accounted for by intrinsic differences between primary cultures. The effect of A83-01 treatment was apparent in principal component 2 (PC2), which accounted for $28 \%$ of the variance in gene expression (Figure 2A). Following Benjamini-Hochberg correction for multiple testing, 1,463 genes were differentially expressed upon A83-01 treatment (Figure 2B), 759 (52\%) of which were upregulated and 704 (48\%) down-regulated. Gene ontology (GO) 
A

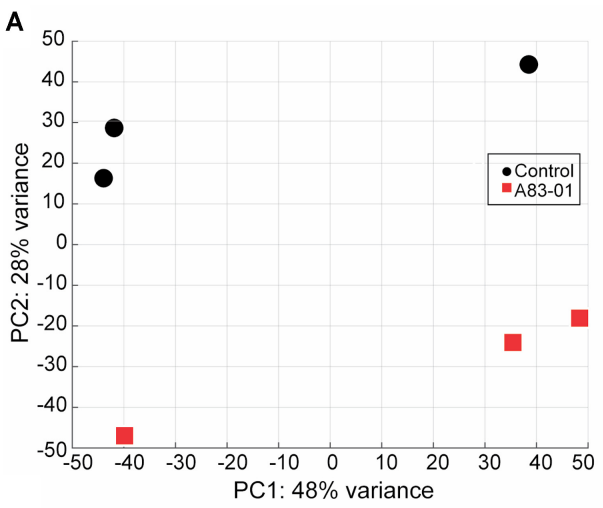

C

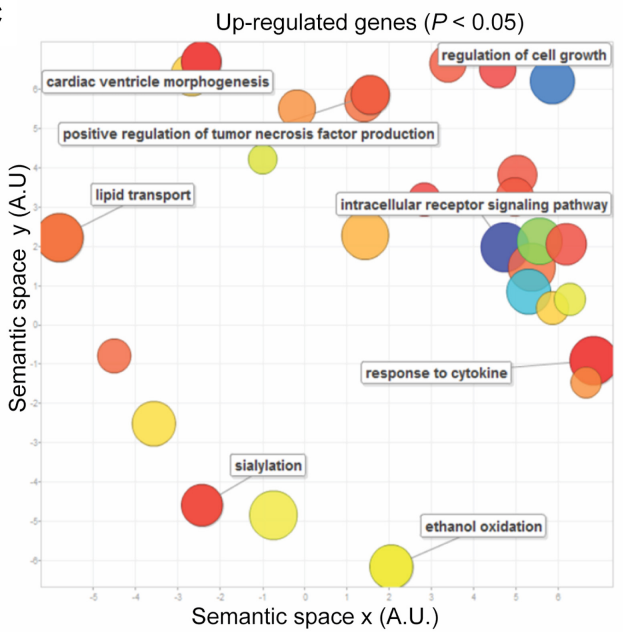

D

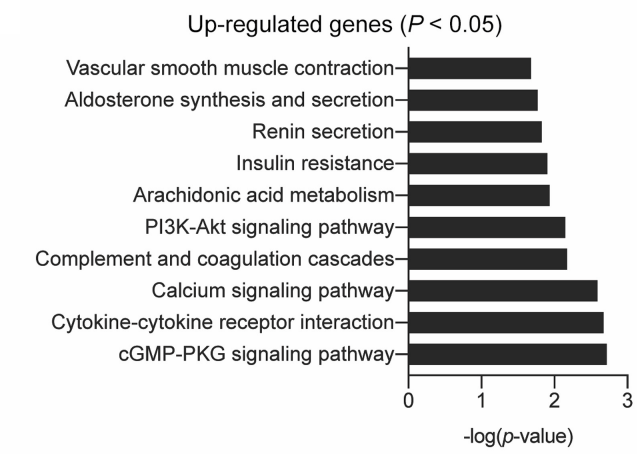

B
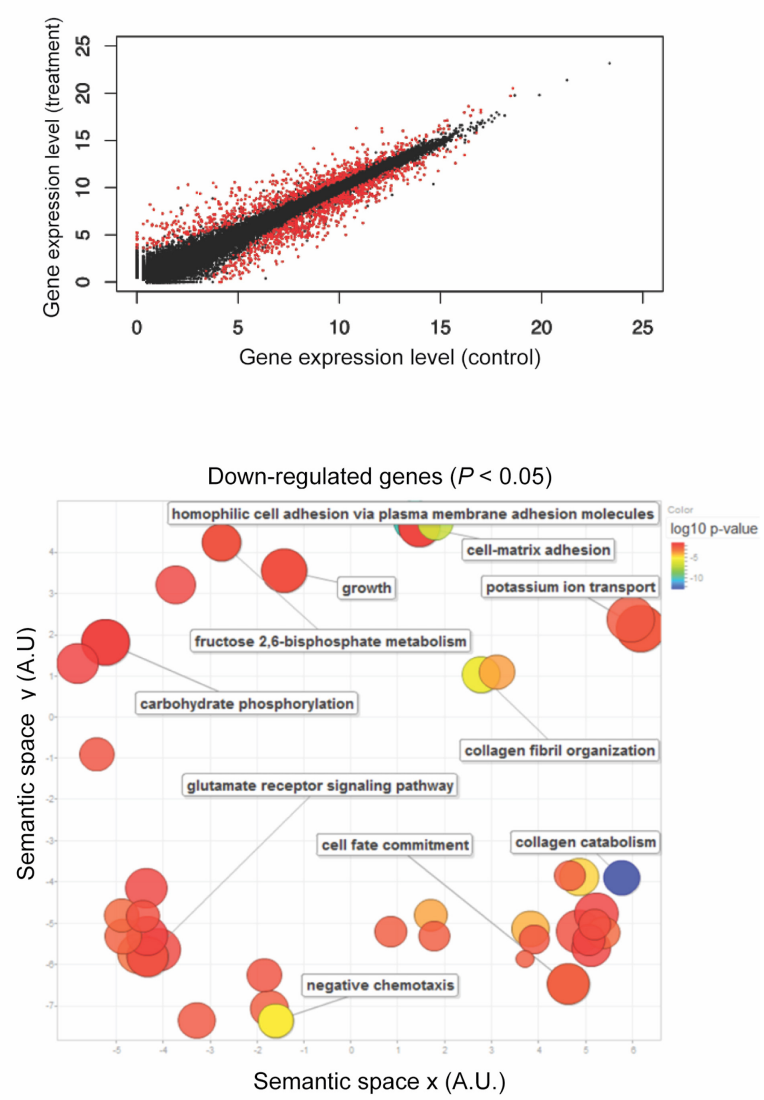

Down-regulated genes $(P<0.05)$

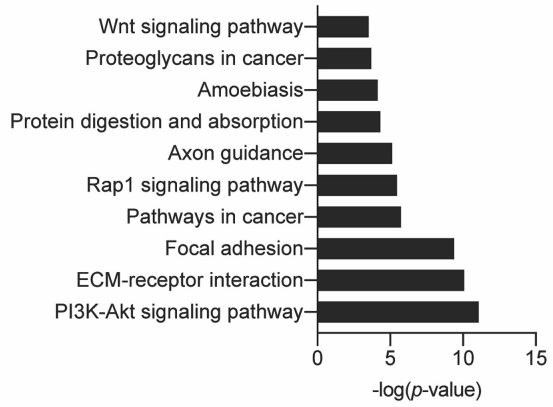

KEGG Pathways associated with up- (left panel) and down- (right panel) regulated genes

FIGURE 2 | Transcriptomic profile of eMSC upon sustained A83-01 treatment. (A) Principal component analysis of RNA-seq data from three independent primary eMSC cultures treated with or without TGF $\beta$-R inhibitor for 36 days. (B) Average gene expression levels expressed as log2 transformed counts normalized to library size between control and A83-01 treated libraries. Red dots represent significantly differentially expressed genes $(q<0.05)$, black dots indicate non-differentially expressed genes. (C) Semantic clustering of significantly overrepresented GO terms $(p<0.05)$ of differentially induced and repressed genes (left and right panel, respectively) upon A83-01 treatment. The color key is shown on the right. The most highly enriched GO categories are indicated in blue. The size of the circles reflects the frequency of the GO term. (D) Enrichment analysis of KEGG pathways associated with up-and down-regulated genes (left and right panels, respectively).

analysis using DAVID revealed that genes induced upon A8301 treatment are enriched in 61 biological processes, including 'regulation of cell growth' $\left(p=7.8 \times 10^{-4}\right)$ and 'intracellular receptor signaling pathways' $\left(p=4.5 \times 10^{-4}\right)$ (Figure 2C, left panel). Conversely, analysis of downregulated genes yielded GO terms such as 'cell fate commitment' $\left(p=4.9 \times 10^{-4}\right)$, 'collagen catabolism' $\left(p=1.7 \times 10^{-13}\right)$, and 'collagen fibril organization' $\left(p=4.6 \times 10^{-6}\right)$ (Figure $2 \mathrm{C}$, right panel). Notably, 20 out of the 43 most significantly down-regulated genes in A83-01 treated eMSC encode extracellular matrix (ECM) components, including various collagen subunits (e.g., COL1A1, COL1A2, COL4A1, COL4A2, COL5A1, COL5A2, COL6A3, and 
COL8A1), secreted protein acidic and cysteine rich (SPARC), and fibronectin (FN) (Supplementary Figure S1). Many of the ECM genes repressed by A83-01 are very highly expressed in untreated eMSC with levels ranging from 342 to 14,586 TPM (Supplementary Figure S1). These data suggest that the effect of TGF $\beta$-R blockade on eMSC is mediated, at least in part, by limiting ECM synthesis and deposition in prolonged culture. As shown in Supplementary Figure S2, several angiogenic, anti-inflammatory, immunomodulatory, antifibrotic and anti-apoptotic genes were significantly upregulated in A83-01-treated cells, in keeping with our previous report (Gurung et al., 2018b).

Further annotation of differentially expressed genes using the KEGG Pathway database underscored the functional differences between A83-01-treated and untreated cultures (Figure 2D). Notable pathways enriched in eMSC in response to sustained TGF $\beta$-R inhibition included the 'cyclic guanosine monophosphate (cGMP)-protein kinase G (PKG) signaling pathway,' which is implicated in nitric oxide-mediated cardioprotection during acute ischemic preconditioning (Sun et al., 2013), cell growth, and inhibition of apoptosis (Wolfertstetter et al., 2013), and 'cytokine-cytokine receptor interaction', in keeping with the innate paracrine function of MSC (Tolar et al., 2010; Mukherjee et al., 2019a). Conversely, A83-01 repressed genes were enriched in 'pathways in cancer,' 'focal adhesion', and 'ECM-receptor interaction.' Notably, the 'PI3K-Akt signaling pathway' was common to both up- and down-regulated genes. This multifaceted pathway controls key cellular processes by phosphorylating substrates involved in apoptosis, protein synthesis, metabolism, and cell cycle. Mining of the RNA-seq data revealed that A83-01 induces several genes involved in activation of response to oxidative stress and cellular detoxification pathways, including ProstaglandinEndoperoxide Synthase 2 (PTGS2), Cytoglobin (CYGB), Scavenger Receptor Class A Member 3 (SCARA3), Glutathione Peroxidase 3 (GPX3), Scavenger Receptor Class A Member 5 (SCARA5) and Apolipoprotein E (APOE). Conversely, multiple senescence-associated genes, including Cyclin Dependent Kinase Inhibitor $1 \mathrm{~A}$ (CDKN1A), Cyclin Dependent Kinase Inhibitor 2B (CDKN2B), Cyclin Dependent Kinase 6 (CDK6), Cyclin D2 (CCND2), Ataxia Telangiectasia Mutated (ATM), tumor protein p53 inducible protein 3 (TP53I3) and phosphatase and tensin homolog (PTEN) were inhibited upon A83-01treatment (Supplementary Table S1 and Supplementary Figures S3A,B). Other senescence associated genes, such as Serpin Family E Member 2 (SERPINE2), and Netrin 4 (NTN4) (Supplementary Figures S3A,B) were also significantly downregulated. This gene signature supports the conjecture that continuous TGF $\beta-R$ inhibition during culture expansion leads to the emergence of senescence-resistant eMSC.

\section{Chromatin Changes Induced by Sustained A83-01 Treatment of eMSC}

Dynamic changes in chromatin structure and epigenetic code drive gene expression and ultimately define cell identity (Chen and Dent, 2014). To map the global changes in the genomic architecture of cultured eMSC in response to sustained TGF $\beta$ $\mathrm{R}$ inhibition, 3 independent eMSC cultures treated with or without A83-01 for 36 days were subjected to ATAC-seq, which profiles chromatin accessible regions as a sequencing depth readout (Vrljicak et al., 2018). Based on $q \leq 0.05$, DESeq identified 5,967 differential ATAC-seq peaks upon A8301 treatment, $60 \%$ of which involved opening of genomic regions and $40 \%$ closing of specific loci. Out of 5,967 peaks, 31 and $29 \%$ of the opening and closing ATAC-seq peaks, respectively, fell within -10 to +1 kilobases $(\mathrm{kb})$ around transcriptional start sites (TSSs). RARB (coding retinoic acid receptor beta, RAR $\beta$ ), TGFBR3 (transforming growth factor beta receptor 3) and SUSD2 exemplify genes that showed increased chromatin accessibility at and upstream of their proximal promoters upon A83-01 treatment (Figure 3A). Cross-referencing with RNAseq data showed a significant increase in $R A R B, T G F B R 3$ and SUSD2 transcript levels in response to A83-01 treatment $\left(q=1.1 \times 10^{-33}, q=1.2 \times 10^{-22}\right.$, and $q=2.7 \times 10^{-5}$, respectively). Conversely, CADM1 (cell adhesion molecule 1), COL1A1 (collagen type I alpha 1 chain), and WNT5A are examples of genes repressed in response to A83-01 treatment $\left(q=1.9 \times 10^{-46}, q=1.4 \times 10^{-9}\right.$, and $q=5.0 \times 10^{-30}$, respectively). As shown in Figure 3B, downregulation of CADM1 and COL1A1 is associated with closure of their proximal promoters whereas silencing of WNT5A coincides with closure of a distal enhancer. Given that A83-01 inhibits senescence and apoptosis upon expansion of eMSC in culture (Gurung et al., 2015), we also searched for differential ATAC-seq peaks in proximal promoters of genes involved in senescence resistance. For example, A83-01 treatment resulted in opening of the proximal PGTS2 (prostaglandin endoperoxidase synthase 2) promoter $\left(q=5.4 \times 10^{-2}\right)$. On the other hand, loss of chromatin accessibility to the CCND2 (cyclin D2) promoter $\left(q=1.1 \times 10^{-2}\right)$ (Supplementary Figure S3C) was also observed.

The gain or loss of ATAC-seq peaks upon A83-01 treatment indicates that altered transcription factor (TF) binding drives differential gene expression. However, both activating and repressive TFs can potentially bind at different regulatory sites, rendering it challenging to confidently predict gene expression from dynamic chromatin changes at specific loci alone (Vrljicak et al., 2018). Nevertheless, analysis of 200 genes associated with the most induced or repressed ATAC-seq peaks (within $10 \mathrm{~kb}$ of TSSs) revealed a strong association with increased or decreased expression, respectively, upon A83-01 treatment $\left(p=1.0 \times 10^{-6}\right)$ (Figure 4). Next, we interrogated the ATACseq data to gain insight into the cis- regulatory landscape that underpins the transcriptional responses of eMSC to sustained A83-01 treatment from culture initiation. De novo binding motif enrichment analysis was performed using HOMER on 3,555 opening and 2,412 closing ATAC-seq peaks. This annotation yielded 19 significantly overrepresented motifs in opening peaks (Supplementary Figure S4), and 17 overrepresented motifs in closing peaks (Supplementary Figure S5).

Next, we matched the motifs against canonical TFs that are differentially expressed in cultured eMSC treated with and without A83-01 (Figure 5A). CCAAT/enhancer binding protein beta and delta $(C E B P B / C E B P D), R A R B$, RAR-related 
Lucciola et al.

TGF $\beta$-R Inhibition in Endometrial MSC
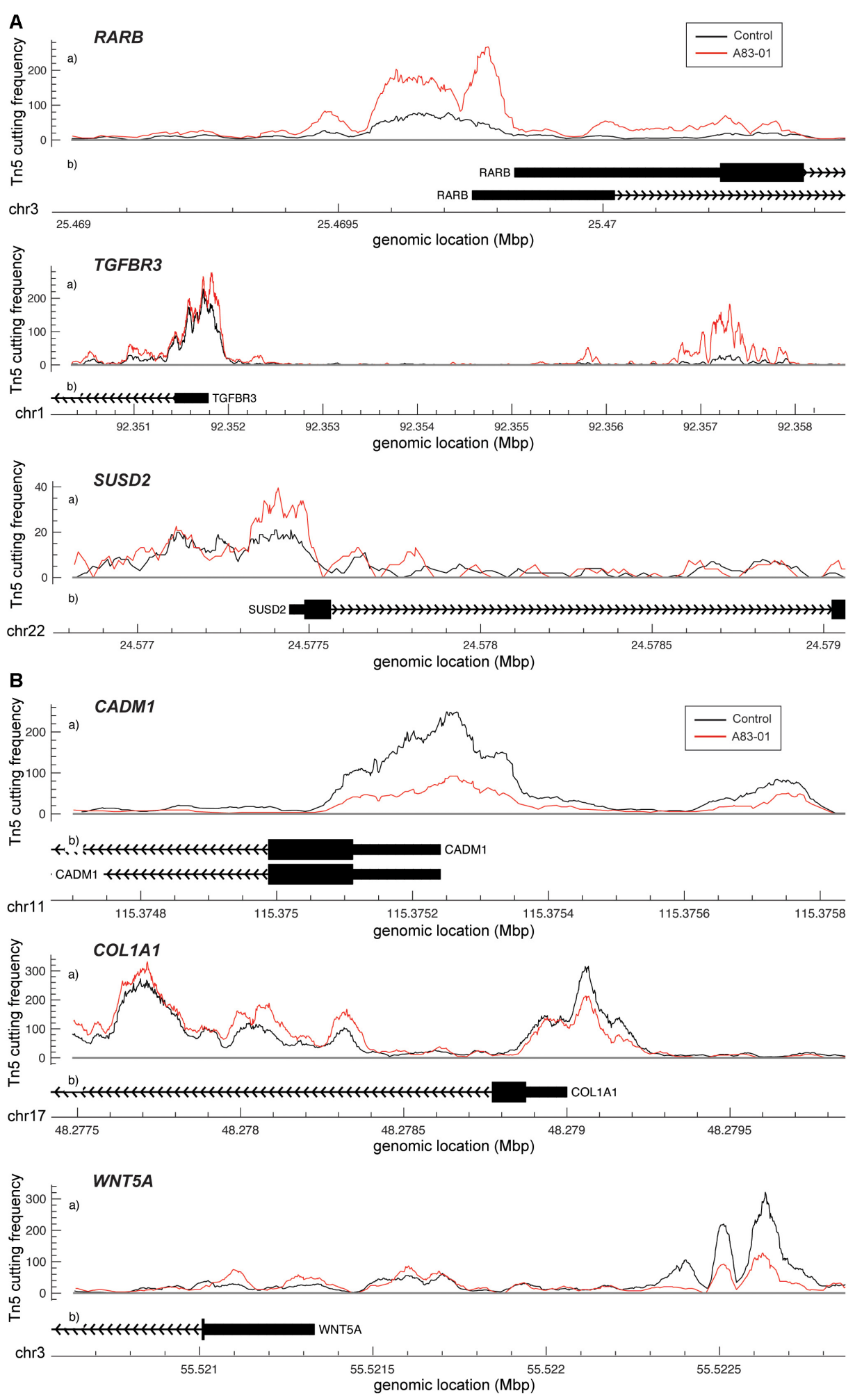

FIGURE 3 | Changes in chromatin accessibility in A83-01 treated eMSC. (A) Representative ATAC-seq peaks showing transition from closing to opening chromatin upstream of the promoter of RARB, TGFBR3 and SUSD2 in response to A83-01. (B) Representative ATAC-seq peaks showing transition from opening to closing chromatin of the proximal promoter of CADM1 and COL1A, and of a distal enhancer of WNT5A in response to A83-01. Black and red traces represent untreated and A83-01-treated eMS cultures. The $X$-axis shows the genomic location of the ATAC-seq peaks and genes. The $Y$-axis shows the frequency of Tn cutting.

Frontiers in Cell and Developmental Biology | www.frontiersin.org

8

September 2020 | Volume 8 | Article 567610 


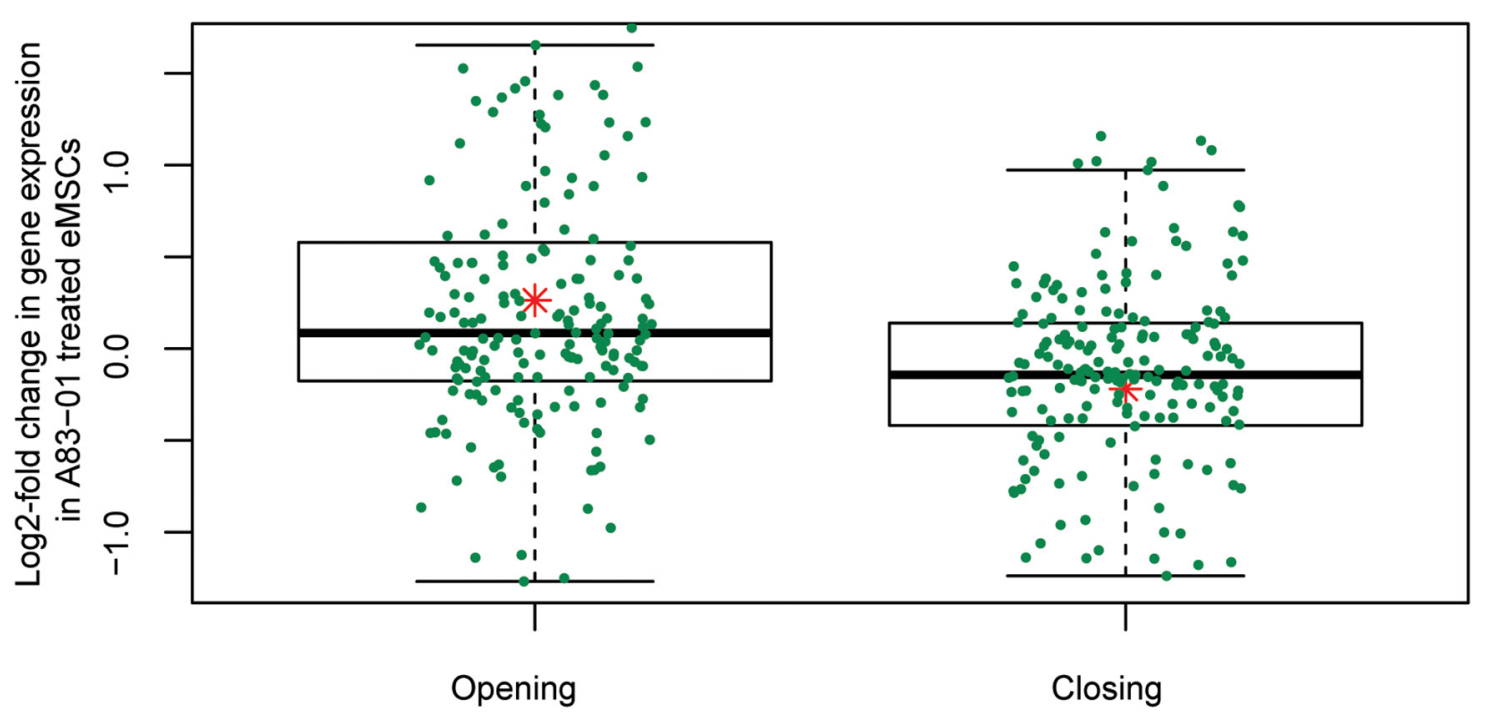

FIGURE 4 | Differential chromatin opening correlates with gene expression changes in A83-01-treated eMSC. Changes in chromatin landscape of eMSC in response to TGF $\beta$-R inhibition correlate with differential regulation of gene expression. Box plots showing increase or decrease in transcript levels of 200 genes (within $10 \mathrm{~kb}$ of the TSS) associated with the most open and closed ATAC-seq peaks. $Y$-axis shows relative changes in transcript levels, expressed as log2-fold change: +ve and -ve values relate to up- and down-regulated genes, respectively. $X$-axis shows ATAC-seq peaks clustered in opening and closing peaks. Green dots represent the genes and the red asterisk represents mean log2-fold change $(p=1.0 \times 10-6, t$-test).

orphan receptor alpha $(R O R A)$, and nuclear receptor subfamily 4 group A member 1 (NR4A1, also known as NUR77) were amongst the most plausible differentially expressed genes of TFs that can bind the enriched motifs in opening ATACseq peaks with high affinity (Figures 5A,B). Conversely, reduced expression of transcription factor 21 (TCF21), TGFB induced factor homeobox 2 (TGIF2), and nuclear transcription factor $\mathrm{Y}$ subunit alpha (NFYA) paralleled the loss of their corresponding binding sites in closing loci (Figures 5A,B).

\section{RAR $\beta$ Is One Mediator of A83-01 Responses in eMSC}

A notable observation was that A83-01 treatment markedly upregulated $R A R B$ expression $\left(q=1.1 \times 10^{-33}\right)$ (Figure 5A) in parallel with genome-wide enrichment of RAR/RORA binding sites $\left(p=1.0 \times 10^{-168}\right)$ (Figure 5B). $\operatorname{RAR} \beta$ is a member of the thyroid-steroid hormone receptor superfamily of nuclear transcription regulators. It binds retinoic acid (RA), the biologically active form of vitamin A (Gudas, 2012). Further, A83-01 induces multiple other genes implicated in RA signaling (Figure 6A), including the cellular retinoic acid binding protein 2 (CRABP2), as well as known RA target genes (Figure 6B). GDF7 (coding growth differentiation factor 7) and MTSS1 (MTSS I-BAR domain containing 1) exemplify RA target genes that exhibited increased chromatin accessibility and expression in A83-01-treated cells (Figure 6C). To explore the effect of RARB on A83-01-treated eMSC further, we utilized LE135, a selective RAR $\beta$ antagonist (Murakami et al., 2013). LE135 had no effect on eMSC proliferation in standard cultures not treated with A83-01. However, addition of LE135 to A83-01 treated cultures indicated that RAR $\beta$ inhibition partially reverses the proliferation advantage conferred by TGF $\beta-\mathrm{R}$ inhibition (Figure 6D). In addition, LE135 reduced the clonogenicity of A83-01 treated eMSC (Figure 6E).

\section{DISCUSSION}

This study demonstrates that eMSC cultured under continuous TGF $\beta$-R inhibition from culture initiation are protected against loss of proliferation and clonogenicity upon longterm expansion. The impact of A83-01 on the phenotype of cultured eMSC was underpinned by an altered chromatin landscape and gene expression. More than 1,400 genes were differentially regulated by culturing eMSC in A83-01containing SFM for 5 weeks, characterized by upregulation of angiogenic, anti-inflammatory, immunomodulatory, antifibrotic and antiapoptotic genes and marked downregulation of ECM genes. The overall signature indicated that A83-01 maintains the expression of genes involved in eMSC paracrine activity while simultaneously inhibiting activation of fibroblast differentiation genes. Over 3,500 regions of chromatin opened while approximately 2,400 genomic loci closed in response to continuous TGF $\beta-R$ inhibition. Motif analysis identified marked enrichment of several putative TF binding sites associated with the more undifferentiated A83-01-treated eMSC, most prominently RAR/ROR. RARB expression was also markedly upregulated in parallel with multiple genes encoding signal intermediates in the RA pathway as well as known RA target genes. Functional assays with a selective RARB inhibitor demonstrated for the first time an integral role for RA signaling in effecting eMSC responses to prolonged A83-01 


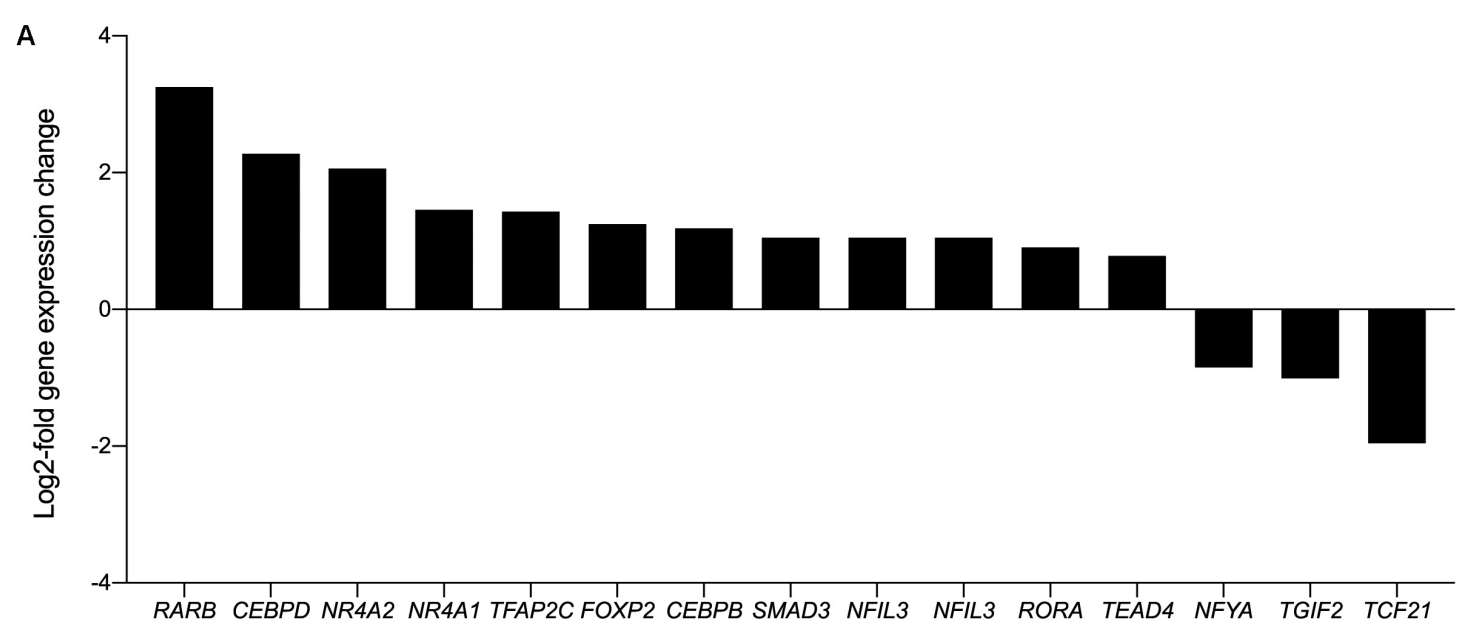

B

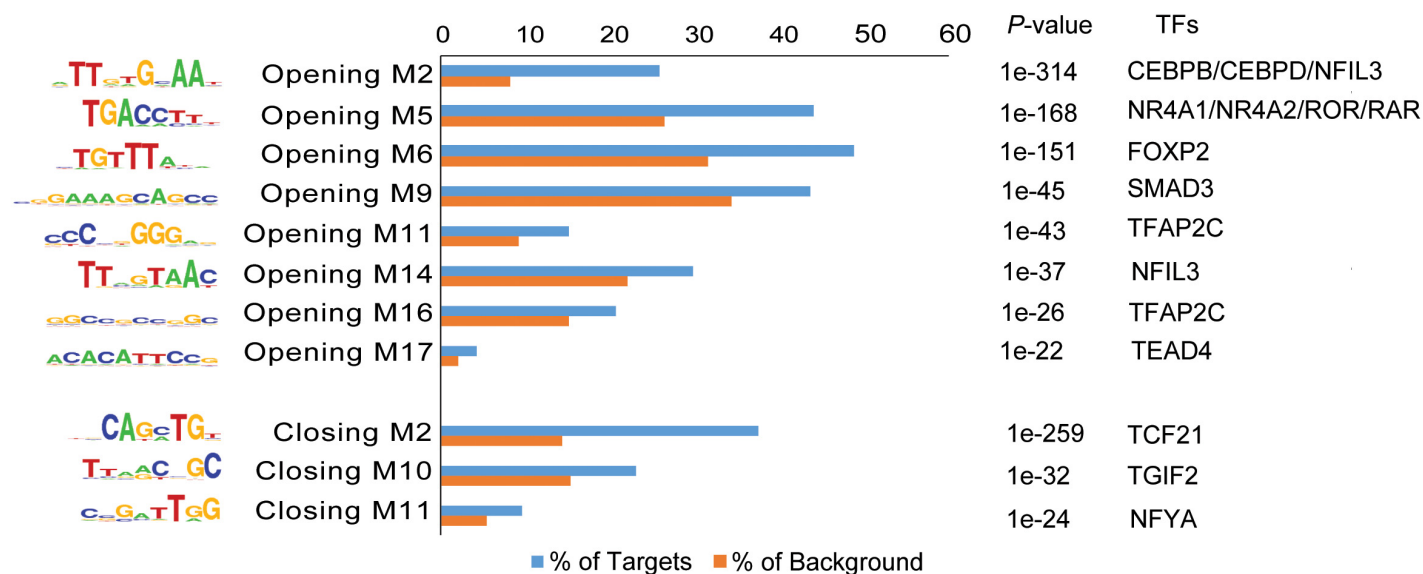

FIGURE 5 | Motif discovery analysis in dynamic genomic regions. (A) Inhibition of TGF $\beta$-R signaling pathway alters expression of genes encoding TFs. Graph shows expression of selected significantly up- and down-regulated TFs (log2-fold change $\geq 1$ and $\leq-1$ ). (B) Differentially regulated TFs matched to enriched and depleted short sequence binding motifs. Bar graph showing enriched and depleted binding motifs coupled with the most plausible differentially expressed TFs, based on motif specificity. In the bar graph, the frequency (\%) of peaks (blue bars) containing the motif is shown relative to genomic regions randomly selected from the genome (orange bars) ( $\pm 50 \mathrm{~kb}$ from TSS, matching size, and GC/CpG content). P indicates the $p$-value of the short sequence binding motifs.

treatment. Thus, sustained inhibition of TGF $\beta-\mathrm{R}$ signaling during eMSC expansion in extended serum-free cultures under physiological $\mathrm{O}_{2}$ conditions produces a relatively homogeneous, undifferentiated population of cells with favorable properties for clinical translation.

We reported previously that short-term treatment with A8301 in SFM (7 days) following extensive culture expansion of eMSC in serum medium (6 passages) increases proliferation and enhances clonogenicity (Gurung et al., 2015). Here we report that sustained TGF $\beta-\mathrm{R}$ inhibition from culture initiation similarly promotes eMSC clonogenicity and proliferation with significant differences observed by passage 3. Although eMSC intrinsically have extensive proliferative capacity in culture, the use of A83-01 enhances this proliferative capacity, increasing cellular output for potential clinical translation (Gargett et al., 2019). Prolonged culture under these conditions also increased the percentage of SUSD2-expressing cells, but not CD140b or the representative ISCT marker CD90, nor the density of these surface markers on the A83-01-treated cells, indicating that the perivascular eMSC phenotype was retained and spontaneous fibroblast differentiation attenuated.

We reported previously that the MFI and percentage of cells positive for certain ISCT surface markers (CD29, CD44, CD73, CD105) are insensitive to culture conditions (Rajaraman et al., 2013). This is also the case for CD90. Similar observations have been reported for adipose, dental pulp, amniotic fluid MSC (Gharibi and Hughes, 2012) and bone marrow MSC (Haniffa et al., 2009). Further, ISCT markers do not discriminate between MSC and differentiated fibroblasts in culture (Haniffa et al., 2009). Likewise, CD90 is expressed in vivo on human endometrial fibroblasts as well as eMSC (Schwab et al., 2008), supporting our in vitro observations. By contrast, we have provided evidence that more recent bone marrow MSC markers, such as TWIST1, TWIST2, and JAG1 (Gurung et al., 2018b), are more indicative of eMSC function. Notably, these marker genes are upregulated within 1 week of culturing in A83-01-containing medium 


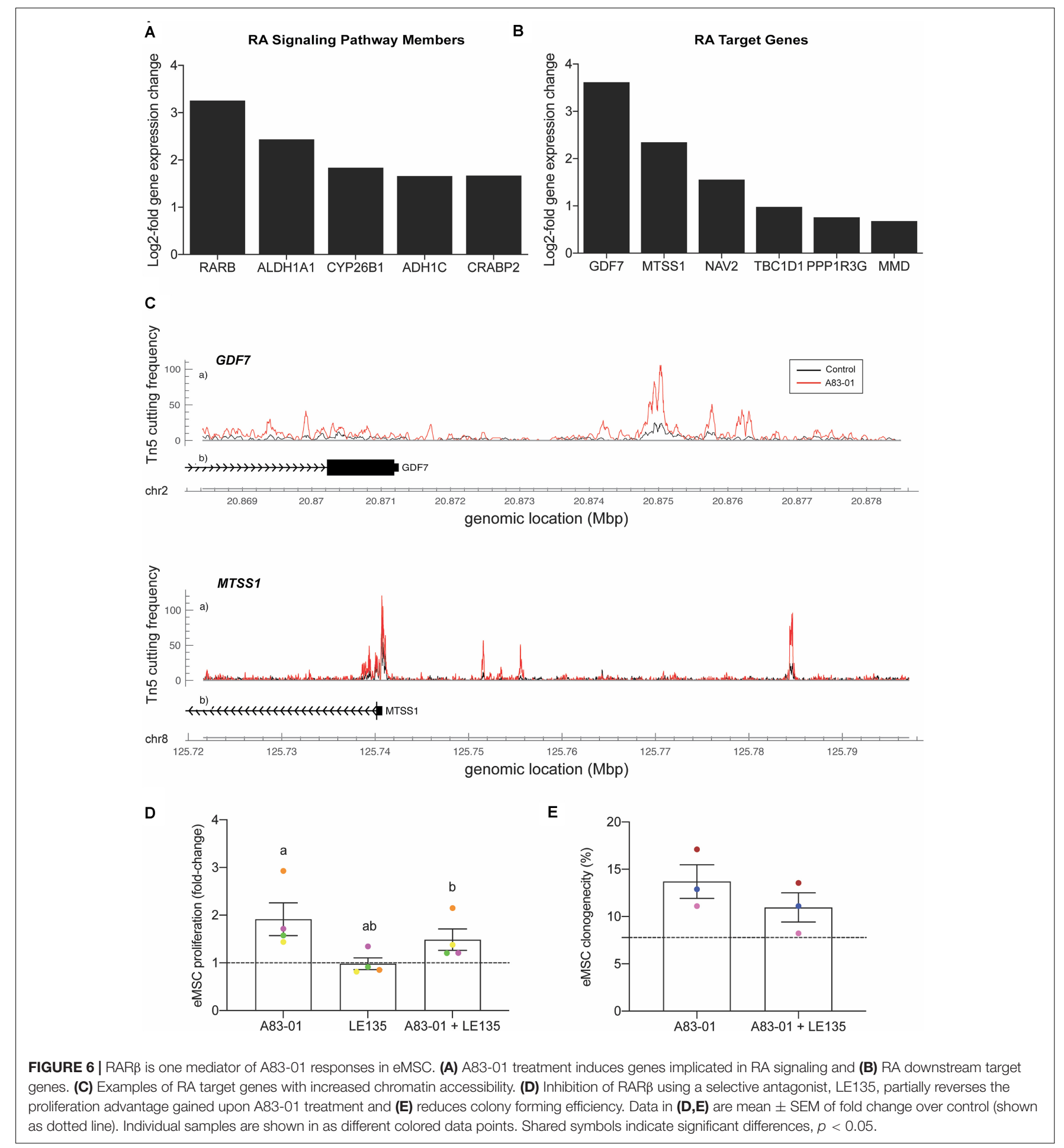

(Gurung et al., 2018b). Currently, SUSD2 is the most sensitive marker to distinguish eMSC from endometrial fibroblasts with the level of expression correlating to the abundance of highly proliferative and clonogenic eMSC in culture (Murakami et al., 2014; Gurung et al., 2015; Bozorgmehr et al., 2020).

Our data for eMSC clonogenicity and proliferation also highlighted intrinsic differences in A83-01 responsiveness between eMSC cultures established from different donors, a wellknown feature of primary MSC cultures (Gargett et al., 2016). Recently it was shown that body mass index of patients, but not age, correlate inversely with the abundance of clonal SUSD2 ${ }^{+}$ eMSC (Murakami et al., 2013). These observations raise the possibility that clinical variables, such as obesity, impact on the in vitro expandability of eMSC. 
The divergent expression of a large number of genes in A83-01-treated cultures suggests either profound transcriptional reprogramming or - perhaps more likely - attenuation of fibroblast differentiation cues imposed by in vitro culture conditions. For example, a striking but not entirely unexpected observation is that A83-01 represses multiple highly expressed genes involved in ECM deposition and collagen metabolism, including 8 collagen subunit genes, FN1, TGFB1 and SPARC. During normal wound healing, TGF $\beta$ signaling is transiently increased to activate fibroblasts (Massague, 2012). Failure to terminate TGF $\beta$ signaling following tissue repair results in chronic activation of fibroblasts, massive accumulation of ECM, and fibrosis. Thus, a likely mechanism of A83-01 actions involves prevention of illicit fibroblast differentiation and activation in extended eMSC cultures. In keeping with previous observations (Gurung et al., 2018b), genes involved in angiogenesis (e.g., SLIT2, HPSE, and SFRP1) (Dufourcq et al., 2008; Urbich et al., 2009; Lv et al., 2018), cell survival (e.g., ENPP2, FAIM2) (Somia et al., 1999; Vidot et al., 2010), and immunomodulation (e.g., TLR3 and IL1R1) (Rameshwar et al., 1997; Farkas et al., 2019) were also upregulated upon prolonged A83-01 treatment. This gene profile infers that sustained TGF $\beta-R$ inhibition leads to expansion of perivascular eMSC that are more efficient in reducing inflammation, promoting wound healing and tissue growth, and minimizing fibrosis when transplanted in vivo. These functional properties are considered cardinal features of MSC, which were recently renamed as Medicinal Signaling Cells to reflect their paracrine activity (Caplan, 2017).

ATAC-seq analysis revealed that TGF $\beta-R$ inhibition in cultured eMSC modifies chromatin accessibility at almost 6,000 genomic regions. The overall pattern, characterized by more opening than closing loci, is in keeping with the less differentiated state of A83-01 treated cells (Chen and Dent, 2014). A strong correlation was observed between changes in gene expression and differentially chromatin accessibility of promoter regions. For example, opening of chromatin at and upstream of the SUSD2 promoter corresponded to increased abundance of SUSD2 ${ }^{+}$ eMSC in A83-01 cultures. Interestingly, SUSD2 has been shown to prevent senescence and cell death in tumor cells (Zhang et al., 2017), suggesting its induction is important for expansion of cultured eMSC.

Furthermore, maintenance of eMSC lifespan during culture expansion under sustained TGFBR inhibition involves upregulation of antioxidant pathways and downregulation of cell cycle arrest pathways that lead to the senescent phenotype of aging MSC (Martínez-Zamudio et al., 2017; Wiese et al., 2019; Cakouros and Gronthos, 2020). For example, A83-01 treatment resulted in opening of the proximal PGTS2 promoter in parallel with increased transcription. By contrast, expression of multiple transcripts involved in the cyclin-dependent kinase inhibitor pathway were repressed, including CCND2, which also showed proximal promoter closing and is associated with MSC senescence (Bertolo et al., 2019). A83-01 effects on chromatin architecture and gene expression may also prevent transcriptome drift that precedes MSC aging (Wiese et al., 2019).

Another potential mechanism that promotes survival of A8301-treated eMSC involves closure of the proximal promoter of
CADM1, which encodes a potent inhibitor of cell proliferation and migration (Murakami, 2005). CADM1 repression is mediated by TWIST1 (Hartsough et al., 2019), a TF upregulated in eMSC in response to A83-01 treatment (Gurung et al., 2018b). The altered cis-regulatory chromatin landscape in response to A8301-induced TGF $\beta$-R blockade also suggested that silencing of specific TFs may be essential to maintain cultured eMSC in an undifferentiated state. A case in point is the loss of TCF21 binding sites in parallel with marked repression of TCF21 expression. TCF21 is a member of basic helix-loop-helix family of transcription factors, which orchestrates cell-fate specification, commitment and differentiation in multiple cell lineages during development (Acharya et al., 2012). Furthermore, TCF21 has recently been shown to drive fibrosis associated with ovarian and deep infiltrating endometriosis (Ganieva et al., 2020).

Our combined RNA- and ATAC-seq analysis identified the RA pathway as a putative pharmacological target to modulate eMSC in culture. A83-01 markedly upregulated $R A R B$ expression in parallel with genome-wide enrichment of putative RORA/RAR binding sites. RA plays an important role during embryonic and fetal development and fine-tunes cellular immune response (Mora et al., 2008). In human endometrium, RA signaling is silenced upon differentiation of endometrial fibroblasts into specialized decidual cells (Vrljicak et al., 2018). Induction of RA target genes in A83-01-treated eMSC confirmed that this signaling pathway is activated endogenously in response to sustained TGF $\beta-R$ inhibition. Further, the selective RAR $\beta$ antagonist, LE135, attenuated the cellular responses to A83-01, indicating that increased or sustained RA-RAR $\beta$ signaling protects eMSC against loss of proliferative capacity and clonogenicity in prolonged culture. Another putative pharmacological target is NR4A1, an orphan nuclear receptor highly induced in A83-01 treated cells. This orphan nuclear receptor exerts pleiotropic regulatory effects on glucose and lipid metabolism (Pei et al., 2006), inflammatory responses (Fassett et al., 2012), and vascular homeostasis (Zeng et al., 2006). Interestingly, NR4A1 inhibits TGF $\beta$ signaling in the nucleus by promoting the assembly of a repressor complex that binds to the promoters of TGF $\beta$ target genes (Palumbo-Zerr et al., 2015). Because of its role as an endogenous TGF $\beta$ inhibitor, small-molecule NR4A1 agonists are under development for the treatment of fibrotic disorders (Palumbo-Zerr et al., 2015).

While the present study shows that A83-01-pretreated eMSC show promise for clinical translation, further research is required to determine their quality, safety and efficacy profile. This includes determining the minimal release criteria such as $\% \mathrm{SUSD}^{+}$cells, secreted proteins and qRT-PCR of key genes that predict efficacy of in vivo function of A83-01-pretreated eMSC. We will also assess the effect of A83-01 withdrawal and reversibility on global chromatin architectural changes and gene expression, and the effect on cryopreservation and thawing. Functional in vivo assays of sustained A83-01-treated eMSC will be assessed using our xenograft mouse model (Gurung et al., 2018a) and in tumorigenicity animal models (Sato et al., 2019). In vitro potency assays that reflect in vivo eMSC function need to be developed, based on their angiogenic and immunomodulatory properties. 
In summary, by integrating genome-wide expression and DNA accessibility profiling techniques, this study has advanced our understanding of the cis-regulatory DNA landscape and gene networks that safeguards eMSC against spontaneous fibroblast differentiation and loss of function in prolonged cultures. Analyses of these two large data sets revealed novel pharmacological targets that could be exploited to accelerate clinical translation of autologous eMSC therapies for a variety of reproductive disorders. Furthermore, the data sets constitute a robust resource to interrogate fundamental molecular questions pertaining to human endometrial biology.

\section{DATA AVAILABILITY STATEMENT}

The datasets presented in this study can be found in online repositories. The names of the repository/repositories and accession numbers can be found in the article/Supplementary Material.

\section{ETHICS STATEMENT}

The studies involving human participants were reviewed and approved by Monash Health and Monash University Human Research Ethics committees. The patients/participants provided their written informed consent to participate in this study.

\section{AUTHOR CONTRIBUTIONS}

RL: collection and assembly of data, data analysis and interpretation, manuscript writing, and final approval of the manuscript. PV: data analysis and interpretation, final approval of the manuscript. SG: data analysis and interpretation, manuscript revision and final approval of manuscript. CF: collection and assembly of data, data analysis and interpretation, manuscript writing, and final approval of manuscript. SD: collection and

\section{REFERENCES}

Acharya, A., Baek, S. T., Huang, G., Eskiocak, B., Goetsch, S., Sung, C. Y., et al. (2012). The bHLH transcription factor Tcf21 is required for lineage-specific EMT of cardiac fibroblast progenitors. Development 139, 2139-2149. doi: 10. 1242/dev.079970

Al-Habib, M., Yu, Z., and Huang, G. T. (2013). Small molecules affect human dental pulp stem cell properties via multiple signaling pathways. Stem Cells Dev. 22, 2402-2413. doi: $10.1089 / \mathrm{scd} .2012 .0426$

Anders, S., and Huber, W. (2010). Differential expression analysis for sequence count data. Genome Biol. 11:R106.

Anders, S., Pyl, P. T., and Huber, W. (2015). HTSeq-a Python framework to work with high-throughput sequencing data. Bioinformatics 31, 166-169. doi: 10.1093/bioinformatics/btu638

Barragan, F., Irwin, J. C., Balayan, S., Erikson, D. W., Chen, J. C., Houshdaran, S., et al. (2016). Human endometrial fibroblasts derived from mesenchymal progenitors inherit progesterone resistance and acquire an inflammatory phenotype in the endometrial niche in endometriosis. Biol. Reprod. 94:118.

Baxter, M. A., Wynn, R. F., Jowitt, S. N., Wraith, J. E., Fairbairn, L. J., and Bellantuono, I. (2004). Study of telomere length reveals rapid aging of human assembly of data, data analysis and interpretation, and final approval of the manuscript. JM: data analysis and interpretation, manuscript editing, and final approval of the manuscript. SO: data analysis and interpretation, final approval of manuscript. JB: conception and design, data analysis and interpretation, manuscript editing, and final approval of manuscript. CG: conception and design, financial support, data analysis and interpretation, manuscript editing, and final approval of manuscript. All authors contributed to the article and approved the submitted version.

\section{FUNDING}

This work was supported by the National Health and Medical Research Council (NHMRC) of Australia Project Grants (IDs 1081944, 1159677 to CG), Senior Research Fellowship (ID 1042298 to CG); and Investigator Grant (ID 1173882 to CG) and the Victorian Government's Operational Infrastructure Support Program, a Chancellor's Warwick-Monash Joint Ph.D. Scholarship (to RL), and a Wellcome Trust Investigator Award (ID $212233 / \mathrm{Z} / 18 / \mathrm{Z}$ to JB and SO).

\section{ACKNOWLEDGMENTS}

We thank the Monash Health Translation Precinct (MHTP) Medical Genomic Facility for the preparation and quality control analysis of RNA and DNA libraries and sequencing. A preprint of this manuscript has been posted on BioRxiv (Lucciola et al., 2020).

\section{SUPPLEMENTARY MATERIAL}

The Supplementary Material for this article can be found online at: https://www.frontiersin.org/articles/10.3389/fcell.2020. 567610/full\#supplementary-material

marrow stromal cells following in vitro expansion. Stem Cells 22, 675-682. doi: 10.1634/stemcells.22-5-675

Bertolo, A., Baur, M., Guerrero, J., Pötzel, T., and Stoyanov, J. (2019). Autofluorescence is a reliable in vitro marker of cellular senescence in human mesenchymal stromal cells. Sci. Rep. 9:2074.

Bozorgmehr, M., Gurung, S., Darzi, S., Nikoo, S., Kazemnejad, S., Zarnani, A. H., et al. (2020). Endometrial and menstrual blood mesenchymal stem/stromal cells: biological properties and clinical application. Front. Cell Dev. Biol. 8:497. doi: 10.3389/fcell.2020.00497

Buenrostro, J. D., Giresi, P. G., Zaba, L. C., Chang, H. Y., and Greenleaf, W. J. (2013). Transposition of native chromatin for fast and sensitive epigenomic profiling of open chromatin, DNA-binding proteins and nucleosome position. Nat. Methods 10, 1213-1218. doi: 10.1038/nmeth.2688

Cakouros, D., and Gronthos, S. (2020). The changing epigenetic landscape of mesenchymal stem/stromal cells during aging. Bone 137:115440. doi: 10.1016/ j.bone.2020.115440

Caplan, A. I. (2017). Mesenchymal stem cells: time to change the name!. Stem Cells. Transl. Med. 6, 1445-1451. doi: 10.1002/sctm.17-0051

Chan, R. W., Schwab, K. E., and Gargett, C. E. (2004). Clonogenicity of human endometrial epithelial and stromal cells. Biol. Reprod. 70, 1738-1750. doi: 10.1095/biolreprod.103.024109 
Chen, T., and Dent, S. Y. (2014). Chromatin modifiers and remodellers: regulators of cellular differentiation. Nat. Rev. Genet. 15, 93-106. doi: 10.1038/nrg 3607

Darzi, S., Deane, J. A., Nold, C. A., Edwards, S. E., Gough, D. J., Mukherjee, S., et al. (2018). Endometrial mesenchymal stem/stromal cells modulate the macrophage response to implanted polyamide/gelatin composite mesh in immunocompromised and immunocompetent mice. Sci. Rep. 8:6554.

Darzi, S., Werkmeister, J. A., Deane, J. A., and Gargett, C. E. (2016). Identification and characterization of human endometrial mesenchymal stem/stromal cells and their potential for cellular therapy. Stem Cells Transl. Med. 5, 1127-1132. doi: 10.5966/sctm.2015-0190

Dufourcq, P., Descamps, B., Tojais, N. F., Leroux, L., Oses, P., Daret, D., et al. (2008). Secreted frizzled-related protein-1 enhances mesenchymal stem cell function in angiogenesis and contributes to neovessel maturation. Stem Cells 26, 2991-3001. doi: 10.1634/stemcells.2008-0372

Emmerson, S., Mukherjee, S., Melendez-Munoz, J., Cousins, F., Edwards, S. L., Karjalainen, P., et al. (2019). Composite mesh design for delivery of autologous mesenchymal stem cells influences mesh integration, exposure and biocompatibility in an ovine model of pelvic organ prolapse. Biomaterials 225:119495. doi: $10.1016 /$ j.biomaterials.2019.119495

Farkas, D., Thompson, A. A. R., Bhagwani, A. R., Hultman, S., Ji, H., Kotha, N., et al. (2019). Toll-like receptor 3 is a therapeutic target for pulmonary hypertension. Am. J. Respir. Crit. Care Med. 199, 199-210.

Fassett, M. S., Jiang, W., D’Alise, A. M., Mathis, D., and Benoist, C. (2012). Nuclear receptor Nr4al modulates both regulatory T-cell (Treg) differentiation and clonal deletion. Proc. Natl. Acad. Sci. U.S.A. 109, 3891-3896. doi: 10.1073/pnas. 1200090109

Ganieva, U., Nakamura, T., Osuka, S., Bayasula Nakanishi, N., Kasahara, Y., et al. (2020). Involvement of transcription factor 21 in the pathogenesis of fibrosis in endometriosis. Am. J. Pathol. 190, 145-157. doi: 10.1016/j.ajpath.2019. 09.008

Gargett, C. E., Gurung, S., Darzi, S., Werkmeister, J. A., and Mukherjee, S. (2019). Tissue engineering approaches for treating pelvic organ prolapse using a novel source of stem/stromal cells and new materials. Curr. Opin. Urol 29, 450-457. doi: $10.1097 / \mathrm{mou} .0000000000000634$

Gargett, C. E., and Masuda, H. (2010). Adult stem cells in the endometrium. Mol. Hum. Reprod. 16, 818-834. doi: 10.1093/molehr/gaq061

Gargett, C. E., Schwab, K. E., and Deane, J. A. (2016). Endometrial stem/progenitor cells: the first 10 years. Hum. Reprod. Update 22, 137-163.

Gargett, C. E., Schwab, K. E., Zillwood, R. M., Nguyen, H. P., and Wu, D. (2009). Isolation and culture of epithelial progenitors and mesenchymal stem cells from human endometrium. Biol. Reprod. 80, 1136-1145. doi: 10.1095/biolreprod. 108.075226

Gharibi, B., and Hughes, F. J. (2012). Effects of medium supplements on proliferation, differentiation potential, and in vitro expansion of mesenchymal stem cells. Stem Cells Transl. Med. 1, 771-782. doi: 10.5966/sctm.20100031

Gudas, L. J. (2012). Emerging roles for retinoids in regeneration and differentiation in normal and disease states. Biochim. Biophys. Acta 1821, 213-221. doi: 10. 1016/j.bbalip.2011.08.002

Gurung, S., Deane, J. A., Darzi, S., Werkmeister, J. A., and Gargett, C. E. (2018a). In vivo survival of human endometrial mesenchymal stem cells transplanted under the kidney capsule of immunocompromised mice. Stem Cells Dev. 27, 35-43. doi: 10.1089/scd.2017.0177

Gurung, S., Williams, S., Deane, J. A., Werkmeister, J. A., and Gargett, C. E. (2018b). The transcriptome of human endometrial mesenchymal stem cells under tgfbetar inhibition reveals improved potential for cellbased therapies. Front. Cell Dev. Biol. 6:164. doi: 10.3389/fcell.2018. 00164

Gurung, S., Werkmeister, J. A., and Gargett, C. E. (2015). Inhibition of transforming growth factor-beta receptor signaling promotes culture expansion of undifferentiated human endometrial mesenchymal stem/stromal cells. Sci. Rep. 5:15042.

Haniffa, M. A., Collin, M. P., Buckley, C. D., and Dazzi, F. (2009). Mesenchymal stem cells: the fibroblasts' new clothes? Haematologica 94, 258-263. doi: 10. 3324/haematol.13699
Hartsough, E. J., Weiss, M. B., Heilman, S. A., Purwin, T. J., Kugel, C. H. III, Rosenbaum, S. R., et al. (2019). CADM1 is a TWIST1-regulated suppressor of invasion and survival. Cell Death Dis. 10:281.

Heinz, S., Benner, C., Spann, N., Bertolino, E., Lin, Y. C., Laslo, P., et al. (2010). Simple combinations of lineage-determining transcription factors prime cisregulatory elements required for macrophage and B cell identities. Mol. Cell. 38, 576-589. doi: 10.1016/j.molcel.2010.05.004

Huang da, W., Sherman, B. T., and Lempicki, R. A. (2009). Systematic and integrative analysis of large gene lists using DAVID bioinformatics resources. Nat. Protoc. 4, 44-57. doi: 10.1038/nprot.2008.211

Jabbour, H. N., Kelly, R. W., Fraser, H. M., and Critchley, H. O. (2006). Endocrine regulation of menstruation. Endocr. Rev. 27, 17-46. doi: 10.1210/er.2004-0021

Langmead, B., and Salzberg, S. L. (2012). Fast gapped-read alignment with bowtie 2. Nat. Methods 9, 357-359. doi: 10.1038/nmeth.1923

Li, H., Handsaker, B., Wysoker, A., Fennell, T., Ruan, J., Homer, N., et al. (2009). The sequence alignment/map format and SAMtools. Bioinformatics 25, 20782079. doi: 10.1093/bioinformatics/btp352

Li, W., and Ding, S. (2010). Generation of novel rat and human pluripotent stem cells by reprogramming and chemical approaches. Methods Mol. Biol. 636, 293-300. doi: 10.1007/978-1-60761-691-7_18

Lucas, E. S., Dyer, N. P., Fishwick, K., Ott, S., and Brosens, J. J. (2016). Success after failure: the role of endometrial stem cells in recurrent miscarriage. Reproduction 152, R159-R166.

Lucciola, R., Vrljicak, P., Filby, C., Darzi, S., Gurung, S., Muter, J., et al. (2020). Impact of Sustained TGF R Receptor Inhibition on Chromatin Accessibility and Gene Expression in Cultured Human Endometrial MSC. Available online at: https://biorxiv.org/cgi/content/short/2020.05.01.073346v1 (accessed May, 2020).

Lv, Q., Wu, K., Liu, F., Wu, W., Chen, Y., and Zhang, W. (2018). Interleukin-17A and heparanase promote angiogenesis and cell proliferation and invasion in cervical cancer. Int. J. Oncol. 53, 1809-1817.

Martínez-Zamudio, R. I., Robinson, L., Roux, P. F., and Bischof, O. (2017). SnapShot: cellular senescence pathways. Cell 170, 816.e-816.e.

Massague, J. (2012). TGFbeta signalling in context. Nat. Rev. Mol. Cell Biol. 13, 616-630.

Masuda, H., Anwar, S. S., Buhring, H. J., Rao, J. R., and Gargett, C. E. (2012). A novel marker of human endometrial mesenchymal stem-like cells. Cell Transplant. 21, 2201-2214. doi: 10.3727/096368911x637362

Mora, J. R., Iwata, M., and von Andrian, U. H. (2008). Vitamin effects on the immune system: vitamins A and D take centre stage. Nat. Rev. Immunol. 8, 685-698. doi: 10.1038/nri2378

Mukherjee, S., Darzi, S., Paul, K., Werkmeister, J. A., and Gargett, C. E. (2019a). Mesenchymal stem cell-based bioengineered constructs: foreign body response, cross-talk with macrophages and impact of biomaterial design strategies for pelvic floor disorders. Interface Focus 9:20180089. doi: 10.1098/rsfs.2018.0089

Mukherjee, S., Darzi, S., Rosamilia, A., Kadam, V., Truong, Y., Werkmeister, J. A., et al. (2019b). Blended nanostructured degradable mesh with endometrial mesenchymal stem cells promotes tissue integration and anti-inflammatory response in vivo for pelvic floor application. Biomacromolecules 20, 454-468. doi: 10.1021/acs.biomac.8b01661

Murakami, K., Bhandari, H., Lucas, E. S., Takeda, S., Gargett, C. E., Quenby, S., et al. (2013). Deficiency in clonogenic endometrial mesenchymal stem cells in obese women with reproductive failure-a pilot study. PLoS One 8:e82582. doi: 10.1371/journal.pone.0082582

Murakami, K., Lee, Y. H., Lucas, E. S., Chan, Y. W., Durairaj, R. P., Takeda, S., et al. (2014). Decidualization induces a secretome switch in perivascular niche cells of the human endometrium. Endocrinology 155, 4542-4553. doi: 10.1210/en.2014-1370

Murakami, Y. (2005). Involvement of a cell adhesion molecule, TSLC1/IGSF4, in human oncogenesis. Cancer Sci. 96, 543-552. doi: 10.1111/j.1349-7006.2005. 00089.x

Ng, F., Boucher, S., Koh, S., Sastry, K. S., Chase, L., Lakshmipathy, U., et al. (2008). PDGF, TGF-beta, and FGF signaling is important for differentiation and growth of mesenchymal stem cells (MSCs): transcriptional profiling can identify markers and signaling pathways important in differentiation of MSCs into adipogenic, chondrogenic, and osteogenic lineages. Blood 112, 295-307. doi: 10.1182/blood-2007-07-103697 
Palumbo-Zerr, K., Zerr, P., Distler, A., Fliehr, J., Mancuso, R., Huang, J., et al. (2015). Orphan nuclear receptor NR4A1 regulates transforming growth factor$\beta$ signaling and fibrosis. Nat. Med. 21, 150-158. doi: 10.1038/nm.3777

Paul, K., Darzi, S., McPhee, G., Del Borgo, M. P., Werkmeister, J. A., Gargett, C. E., et al. (2019). 3D bioprinted endometrial stem cells on melt electrospun poly $\varepsilon$-caprolactone mesh for pelvic floor application promote anti-inflammatory responses in mice. Acta Biomater 97, 162-176. doi: 10.1016/j.actbio.2019.08. 003

Pei, L., Waki, H., Vaitheesvaran, B., Wilpitz, D. C., Kurland, I. J., and Tontonoz, P. (2006). NR4A orphan nuclear receptors are transcriptional regulators of hepatic glucose metabolism. Nat. Med. 12, 1048-1055. doi: 10.1038/nm1471

Rajaraman, G., White, J., Tan, K. S., Ulrich, D., Rosamilia, A., Werkmeister, J., et al. (2013). Optimization and scale-up culture of human endometrial multipotent mesenchymal stromal cells: potential for clinical application. Tissue Eng Part C Methods 19, 80-92. doi: 10.1089/ten.tec.2011.0718

Rameshwar, P., Poddar, A., Zhu, G., and Gascón, P. (1997). Receptor induction regulates the synergistic effects of substance P with IL-1 and platelet-derived growth factor on the proliferation of bone marrow fibroblasts. J. Immunol. 158, 3417-3424.

Sato, T., and Clevers, H. (2013). Growing self-organizing mini-guts from a single intestinal stem cell: mechanism and applications. Science 340, 1190-1194. doi: 10.1126/science.1234852

Sato, Y., Bando, H., Di Piazza, M., Gowing, G., Herberts, C., Jackman, S., et al. (2019). Tumorigenicity assessment of cell therapy products: The need for global consensus and points to consider. Cytotherapy 21, 1095-1111. doi: 10.1016/j. jcyt.2019.10.001

Schwab, K. E., and Gargett, C. E. (2007). Co-expression of two perivascular cell markers isolates mesenchymal stem-like cells from human endometrium. Hum. Reprod. 22, 2903-2911. doi: 10.1093/humrep/dem265

Schwab, K. E., Hutchinson, P., and Gargett, C. E. (2008). Identification of surface markers for prospective isolation of human endometrial stromal colonyforming cells. Hum. Reprod. 23, 934-943. doi: 10.1093/humrep/den051

Simoni, M., and Taylor, H. S. (2018). Therapeutic strategies involving uterine stem cells in reproductive medicine. Curr. Opin. Obstet. Gynecol. 30, 209-216.

Sobiesiak, M., Sivasubramaniyan, K., Hermann, C., Tan, C., Orgel, M., Treml, S., et al. (2010). The mesenchymal stem cell antigen MSCA-1 is identical to tissue non-specific alkaline phosphatase. Stem Cells Dev. 19, 669-677. doi: $10.1089 /$ scd.2009.0290

Somia, N. V., Schmitt, M. J., Vetter, D. E., Van Antwerp, D., Heinemann, S. F., and Verma, I. M. (1999). LFG: an anti-apoptotic gene that provides protection from Fas-mediated cell death. Proc. Natl. Acad. Sci. U.S.A. 96, 12667-12672. doi: 10.1073/pnas.96.22.12667

Su, K., Edwards, S. L., Tan, K. S., White, J. F., Kandel, S., Ramshaw, J. A. M., et al. (2014). Induction of endometrial mesenchymal stem cells into tissueforming cells suitable for fascial repair. Acta Biomater 10, 5012-5020. doi: 10.1016/j.actbio.2014.08.031

Sun, J., Aponte, A. M., Kohr, M. J., Tong, G., Steenbergen, C., and Murphy, E. (2013). Essential role of nitric oxide in acute ischemic preconditioning: S-nitros(yl)ation versus sGC/cGMP/PKG signaling? Free Radic Biol Med 54, 105-112. doi: 10.1016/j.freeradbiomed.2012.09.005

Supek, F., Bošnjak, M., Škunca, N., and Šmuc, T. (2011). REVIGO summarizes and visualizes long lists of gene ontology terms. PLoS One 6:e21800. doi: 10.1371/ journal.pone.0021800
Thurman, R. E., Rynes, E., Humbert, R., Vierstra, J., Maurano, M. T., Haugen, E., et al. (2012). The accessible chromatin landscape of the human genome. Nature 489, 75-82.

Tolar, J., Le Blanc, K., Keating, A., and Blazar, B. R. (2010). Concise review: hitting the right spot with mesenchymal stromal cells. Stem Cells 28, 1446-1455. doi: $10.1002 /$ stem.459

Ulrich, D., Edwards, S. L., Su, K., Tan, K. S., White, J. F., Ramshaw, J. A., et al. (2014). Human endometrial mesenchymal stem cells modulate the tissue response and mechanical behavior of polyamide mesh implants for pelvic organ prolapse repair. Tissue Eng Part A 20, 785-798.

Ulrich, D., Rikeish, M., and Gargett, C. E. (2013). Toward the use of endometrial and menstrual blood mesenchymal stem cells for cell-based therapies. Expert Opin. Biol. Ther. 13, 1387-1400. doi: 10.1517/14712598.2013.82 6187

Urbich, C., Rössig, L., Kaluza, D., Potente, M., Boeckel, J. N., Knau, A., et al. (2009). HDAC5 is a repressor of angiogenesis and determines the angiogenic gene expression pattern of endothelial cells. Blood 113, 5669-5679. doi: 10. 1182/blood-2009-01-196485

Vidot, S., Witham, J., Agarwal, R., Greenhough, S., Bamrah, H. S., Tigyi, G. J., et al. (2010). Autotaxin delays apoptosis induced by carboplatin in ovarian cancer cells. Cell. Signal. 22, 926-935. doi: 10.1016/j.cellsig.2010. 01.017

Vrljicak, P., Lucas, E. S., Lansdowne, L., Lucciola, R., Muter, J., Dyer, N. P., et al. (2018). Analysis of chromatin accessibility in decidualizing human endometrial stromal cells. FASEB J. 32, 2467-2477. doi: 10.1096/fj.20170 $1098 \mathrm{r}$

Wiese, D. M., Ruttan, C. C., Wood, C. A., Ford, B. N., and Braid, L. R. (2019). Accumulating transcriptome drift precedes cell aging in human umbilical cordderived mesenchymal stromal cells serially cultured to replicative senescence. Stem Cells Transl. Med. 8, 945-958.

Wolfertstetter, S., Huettner, J. P., and Schlossmann, J. (2013). cGMP-Dependent protein kinase inhibitors in health and disease. Pharmaceuticals 6, 269-286. doi: 10.3390/ph6020269

Zeng, H., Qin, L., Zhao, D., Tan, X., Manseau, E. J., Van Hoang, M., et al. (2006). Orphan nuclear receptor TR3/Nur77 regulates VEGF-A-induced angiogenesis through its transcriptional activity. J. Exp. Med. 203, 719-729. doi: 10.1084/ jem. 20051523

Zhang, S., Zeng, N., Alowayed, N., Singh, Y., Cheng, A., Lang, F., et al. (2017). Downregulation of endometrial mesenchymal marker SUSD2 causes cell senescence and cell death in endometrial carcinoma cells. PLoS One 12:e0183681. doi: 10.1371/journal.pone.0183681

Conflict of Interest: The authors declare that the research was conducted in the absence of any commercial or financial relationships that could be construed as a potential conflict of interest.

Copyright (c) 2020 Lucciola, Vrljicak, Gurung, Filby, Darzi, Muter, Ott, Brosens and Gargett. This is an open-access article distributed under the terms of the Creative Commons Attribution License (CC BY). The use, distribution or reproduction in other forums is permitted, provided the original author(s) and the copyright owner(s) are credited and that the original publication in this journal is cited, in accordance with accepted academic practice. No use, distribution or reproduction is permitted which does not comply with these terms. 